\title{
TEXTUAL EQUIVALENCE IN THE TRANSLATION OF ENGLISH TEXTS INTO INDONESIAN
}

\author{
Herlyn Triastika
}

PGRI University of Palembang

triastikaherlyn@gmail.com

\begin{abstract}
This research aims to determine textual equivalence in the translation of scientific texts in English into Indonesian in depth. This study used a qualitative approach using the content analysis method. The data to the analysis performed in this study based on the six-step qualitative research developed by Myring. The findings in this study indicate that: (1) The equivalence of thematic structure contained in the translation of textbooks Approaches to Discourse into Indonesian is the equivalence on the pattern/ thematic arrangement of the unmarked theme and a simple theme/topical theme, (2) the information structure equivalence Between source text (ST) and target text (TT) is the equivalence in the form of organization of given and new information. (3) Equivalence in the cohesive devices translation is found in the use of grammatical cohesive devices, (4) The translation method used is the literal translation, (5) The discovered distortion was fully related to the aspects of semantics and linguistic equivalents, (6) The factors causing distortion are the translators' skills and competencies, (7) The impact inflicted by the various distortion in the target text (TT) is that the translation readersget different messages from the message of source text (ST).
\end{abstract}

Keywords: textual equivalence, thematic structure and information structure, cohesion.

Translation can be interpreted as a process of changing from one form to another, or changing from one language into another. Furthermore, according to Munday (2008: 5), the process of translation between two different written language involves changes to a written text of the original or source text (TS) in verbal language text of these sources language (SL) into a written target text (TT) in different verbal languages (the target language of the TT).

Furthermore, it can also be stated that translation is a process of changing from one form to another, or changing from one language into another. The change always involves at least two different languages, which have a different culture, original language and targeted language. Translation also involves two different people, the author in the original language and the translator. Although it involves different things, the message or transferred meanings must be the same.

Similar opinion submitted by House. In House view (2009: 4-9), translation is the process of replacing a text in a language with a text in another language. The House emphasizes that what should be replaced is the whole text, not the parts or the main elements of the text.

The message or meaning to be conveyed by the translator is in the text (written and oral). The text is the one which should be translated, not the language. (Nida 2001: 3). Understanding and translating texts is complex. According to Newmark (1988: 5), in the context of the translation, the text is something that has dynamics or what he called the theory of "The Dynamics of Translation". In this theory, Newmark (in Hoed: 2006: 42-26) states there are ten factors that affect the meaning of a 
text, four from the source text (ST) side and four from the target text (TT) side, while the other two factors are factors that are outside the ST and TT.

In doing their task, the translators must work with lexical forms and grammatical structures at various stages, and must present equivalenceat word level and grammatical structure. However, according to Baker (2011: 122), the main task of the translator is to present equivalence at the text level. This indicates that the whole process of translation must be initiated and terminated by the text.

In relation to equivalence at the textual level or textual equivalence, it can be stated that the equivalence of the lexical and the grammatical structure does not necessarily present textual equivalence in a target text (TT). It also indicates that the text that should be produced by the translator is the text that has the consistency of cohesion and information (Panou: 2013: 4).

Elements forming the textual correspondences which are contained in a text consist of: (1) The thematic structure with aspects of theme and rhyme contained in each clause; (2) the information structure presentation that reflects the given iand new information; (3) cohesivedevices as a means that has an important role in creating cohesion and coherence of the text (Baker: 2011, 131).

Seeing how important textual equivalence with forming elements in delivering a message that is worth, then the book entitled Ancangan Kajian Wacana as a target text (TT) of Approaches to Discourseshould have this kind of equivalence.However, based on the author's preliminary observations the delivery of the information contained in Ancangan Kajian Wacana as the translation of the book entitled Approaches to Discourseis not yet fully described things as mentioned above. It can be seen from the information contained in Ancangan Kajian Wacana. The information contained in this book is different from the information contained in Approaches to Discourse (TS). In addition, there are unacceptable forms according to Indonesian (TL) rules. Thus as a product of translation that used by translation clients, the text reliability of this book is questionable.

This different information can be caused by deviations on the thematic elements, especially on the part that should represent what the theme says. In addition, it can also be caused by the translator's inaccuracy in diverting the meaning of words, phrases, and sentences contained in the TS. Furthermore, the different information may also be caused by the inappropriate use of translation methods and strategies by the translator.

In relation to the above matters, the researcher is interested in conducting research on textual equivalence in translating English text into Indonesian. In this case, the English text is the text book entitled Approaches to Discourse and the Indonesian text is Ancangan Kajian Wacana.

Moreover, this research is also done with the assumption that the theory on textual equivalence, should also be supported by doing a study examining matters relating to or associated with the correspondences textual equivalence, besides delivering it through teaching and practicing. Soit will give a deeper understanding of textual equivalence in translation, especially textual equivalence in the translation of scientific texts involving English and Indonesian.

A deep understanding of textual equivalence gained through the study of a target text will provide a tangible, detailed, and profound picture of everything related to textual equivalence, a picture that may be different from the theories described by translation experts so far.

\section{METHOD}

This research uses qualitative approach by using content analysis method. In the study of this form, content analysis is performed on the target text to know the elements in the target language that have similarities with the source language elements. These elements can be in the form of correspondence between the source language (SL) and the target language (TL) or the correspondence of the elements in both languages. Qualitative content analysis research is selected because this research is a study conducted in the translation domain. According to William and Chesterman (2002: 
49-50), is based on three main models in the study of translation which include: (1) comparative models; (2) process models; and (3) and causal models. This research is categorized as comparative models.

The procedure used in this study follows six qualitative research steps developed by Myring (in Emzir: 2010,289). The six steps are: (1) determining the research question, determining the object or determining the research focus, (2) defining the theoretical definition of the aspects of analysis, the main categories and subcategories, (3) determining the definition theory formulas, examples, and coding The rules for those categories and collect them in the coding agenda, (4) make revisions of categories and codes of the agenda with formative checks of reliability, (5) do final work via text with a summative check of reliability, and (6) interpret the results, With an evaluation of the quantitative analysis stage (such as frequency).

Data analysis conducted in this research refers to textual equivalence content analysis technique between target text and source text. The textual equivalence form used is the textual equivalence proposed by Mona Baker. Based on this concept, clauses and phrases contained in source text (ST) and target text (TT) are analyzed to find textual equivalence elements, which consist of: (1) the equivalence of thematic structures; (2) the equivalence of the information structure; (3) the equivalence of cohesive devices.

The steps used to find correspondence with the elements mentioned above are to analyze the sentences and clauses in each paragraph of the ource text and target text to define and classify thematic structures, patterns of information structures and cohesive devices.

The analysis was also conducted on sentences and clauses on the TT to find out the methods and strategies used in this translation. In addition, the researcher also identifies the disproportionate forms found in this translation, to determine the form of deviation and classify it according to the category of deviation. Further determined the factors causing and the impact it caused.

To prove that what is observed by the researcher in accordance with what is in reality and in accordance with the actual/existing, conducted examination of the validity of data. Examination of data validity in this study includes credibility, transferability, dependability, and conformability.

\section{RESULT AND DISCUSSION}

Based on the results of the analysis that has been done, obtained data in the form of pattern/arrangement of thematic structure, information structure, and translation of cohesion marker, the findings are then analyzed to determine textual equivalence in the translation of text book entitled Approaches to Discourse into Indonesian. In addition to textual equivalence elements, the results of this analysis are used to identify the following: (1) the methods and strategies used by the translator; (2) deviations of the textual equivalence contained in the translation results; (3) factors causing deviation; and (4) the impact caused by such deviations.

\section{Equivalence of Thematic Structure in the Translation of the TextBook EntitledApproaches to Discourse into Indonesian.}

The results show that there is a TS thematic pattern that can be reproduced or maintained by the translator without causing deviation on the TT. In addition to a sustainable pattern, the findings in this study also show that there is a formal correspondence between the thematic patterns of TS and TT. In this case, it can be said that the translator reproduces the same thematic pattern, but this same pattern does not produce the same or equivalent type of theme.

Patterns of TS thematic organization that can be reproduced or maintained by the translator are unmarked theme. Furthermore, the translator also the pattern / arrangement of theme-rhyme 
(thematic) TS that can be reproduced or maintained by the translator at the TT are contained in the sentence pattern which has the theme in the form of a simple theme / topical theme.

Next, the pattern/TS thematic organization can be reproduced or maintained by the translator at the TT is the marked theme. Although this pattern can be maintained, the elements contained in the TT cannot be categorized as marked theme element. This placement only produces a formal alignment to the pattern / arrangement of themes of TS and TT. Basically, the presence of formal correspondence on the elements of textual equivalence in translation Approaches to Discourse text books into Indonesian, cannot be separated from the concept of the theme-rhyme Halliday as reference in this study. Based on this concept, the theme is whatever lies at the beginning of a sentence, and vice versa, whatever is at the beginning of the sentence is the theme.

Thus, in translating the book titled Approaches to Discourse in to Indonesian, there are equivalence on the pattern/thematic organization of of unmarked theme and simple themeltopical theme. Meanwhile, for the pattern/thematic organization with the type of marked theme and multiple themes contained only formal correspondence between the pattern/ thematic organization of ST and TT.

\section{Information Structure Equivalence in the Translation of the Text Book Entitled Approaches to Discourse into Indonesian.}

The findings of the study and the book titled Approaches to Discourse show that the writer (in this case Deborah Schiffrin), has a way that is not much different from the other writers in packing the information that will be delivered to the readers. This means that Schiffrin using pattern/composition that is generally used by the author in conveying information to readers, by placing the information is already known (given) before the new information ( $\mathrm{New}$ ).

The equivalence of the information structure that exists between TS and TT is the equivalence in the form of a structure of given information and new information with various variations. Redirecting the meaning of TS through the forms chosen by the translator in a particular sentence may alter the pattern / arrangement of the information structure on the TT. Meanwhile, in other sentences the structure of information structure TS and TT did not undergo fundamental changes. However, this option may cause distortion of information on TT. Appropriate placement does not guarantee the equivalence of content / messages.

\section{Equivalence of Cohesive Devices in the translation of the book Entitled Approaches to Discourse into Indonesian.}

The findings of this study indicate that the cohesive devicescontained in the ST as well as the cohesive devices in TT is grammatical cohesive devices. This shows that there is no change or shift in the form of grammatical cohesive devices into the form of lexical cohesive devices in translation textbooks entitled Approaches to Discourseinto Indonesian.

Although there is no such change or shift as mentioned above, there is a change in the translation of the ST cohesive devices into the TT. The change is marked by the difference in the number. This difference indicates a difference between the cohesive devicescontained in English (SL) and Indonesian (TL). This difference is due to grammatical rules applicable to English and Indonesia.

That is, in terms of form there is no change or shift in the translation of the ST cohesivedevices into the TT. Although there is no change from the form of the grammatical cohesive devices to the lexical cohesive devices, there is a difference in numbers. This distinction does not entirely indicate the incompatibility in translation of TS and TT cohesive devices. This makes it clear that the differences are caused by various things. In this case the difference is due to grammatical rules applicable in English and Indonesia, socio-cultural norms, and the prevalence of use. 


\section{Translation Methods and Strategies Used in the Translation of the Text Book entitled Approaches to Discourse into Indonesian.}

In translating the book Approaches to Discourse into Indonesian, translator uses methods that emphasis to the BS or oriented to the BS, the method of literal (literal translation). The use of literal methods in this translation is reflected from the TT still tied to the grammatical structure of the BS, as well as the meaning of words and phrases in TT that are independent of the context. In addition, the transfer of word or phrase meaning to ST is done by giving one-on-one equivalent of the word or phrase.

Translator also does not apply or use certain strategies in translating book Approaches to Discourse into Indonesian. This is due to the use of a literal method identical to the pre-translation stage or the stage where the translator still has to take other steps so that messages on the ST can be delivered in a reasonable and acceptable form in target language (TL). These steps reflect the strategies used or applied by the translator in transferring the message/information contained in the TT.

\section{Textual Equivalence Deviations which are found in Translated Result.}

Deviations textual correspondences contained in the translation of the text book entitled Approaches to Discourse is an aberration which is not directly related to the pattern or arrangement of thematic structure, information structure and cohesive devices translation contained in the TT. Those are irregularities contained in the translation of the book Approaches to Discourse into Indonesian, fully irregularities related to aspects of semantics and linguistic equivalent (grammatical structure). These deviations consist of: (1) aberrations of referential meaning; (2) deviation of grammatical meanings; (3) unacceptable form in BT; (4) does not translate the word or phrase contained in the source text. Thus it can be said that the deviation found in the TT, is not a deviation directly related to textual equivalence elements.

\section{Factors Causing Deviations}

Based on an analysis of various irregularities contained in the translation of the text book Approaches to Discourse found five factors that cause such deviations. The first is the lack of mastery of translators of SL and TL, in this case English and Indonesian. Secondly, the lack of the translator's knowledge about the field he translated. Third, the translators' skills are low to write in BT. Fourth, the translator's inability to use or apply the translation theory. Fifth, the translatorsare not able to utilize and use various dictionaries and resources. Broadly speaking, these five factors relate to the skills and competencies of the translator. In this case, it can be said that the translators involved in the translation of the text book titled Approaches to Discourse into Indonesian, yet have adequate skills and competence to produce good translation.

\section{Textual Deviations Impact on the Translation of the Text Book Entitled Approaches to Discourse into Indonesian.}

The various irregularities contained in the TT, have had an impact in the translation of Approaches to Discourse textbooks into Indonesian. The results show that this deviation has an impact on translation users, TS writers, and targeted subtitles.

The impact for translation users is that they get messages/ information that are different from the messages/information contained on the ST. In addition, readers who should have gained more indepth knowledge of the various matters relating to the discourse analysis are finding inaccurate information. They do not get a text that is 'not reliable'. So they will not get what they want from the TT they read. It can be said that what readers get in the BS, will not be the same as what readers get in BT.

Meanwhile, for the writer TS, the translation of his work into Indonesian, becomes useless, since the purpose of distributing knowledge about the discourse analysis is not fulfilled. This goal is 
important for every writer. This objective should be properly communicated by the translator through the target text it produces through the translation process.

As for the text itself, the impact is the non-fulfillment of textual elements as the builder or the constructor of the text. In this case, the target text or generated translation cannot be categorized as a text. So the translation of text does not produce text anyway.

\section{CONCLUSION}

Based on the findings of this research, the researcher conveys the conclusions related to textual equivalence in translating English subtitles into Indonesian. Based on the findings of the translation of the text book entitled Approaches to Discourse into the Indonesian, it can be concluded that 1) equivalence thematic structure contained in the translation of the text book titled Approaches to Discourse into Indonesian is the equivalence on the pattern/composition of thematic type of theme (unmarked theme) and simple themeltopical theme, to pattern/ composition of thematic with the kind of theme (marked theme) and multiple theme only are there parallels formal (formal correspondence) between the pattern / composition of thematic TS and TT, 2) equivalence of information structure TS and TT contained in the translation of the text book entitled Approaches to Discourse into Indonesian is equivalence in the form of the organization of given and new information with different variations, 3) cohesive devices contained in the ST and TT are cohesive grammar devices, 4) the method used in translation of textbooks entitled Approaches to Discourse into Indonesian is a translation method that emphasis to the SL or oriented SL, the literal/ literal translation, 5) irregularities contained in the translation of the book Approaches to Discourse into Indonesian was an aberration Which is fully related to the semantic and linguistic equivalent aspects (grammatical structure), this deviation consists of: (a) aberrations of referential meaning; (d) deviation of grammatical meanings; (c) unacceptable form in BT; (d) not translating words or phrases contained in the source text, 6) five factors causing this deviation is a) lack of command interpreter against BS and BT, in this case English and Indonesian, b) lack of knowledge of the translator on the field translated , c) the inability of the translator to write in the BT, d) the inability of the translator to use or apply the theory of translation, e) the inability of the translator to utilize and use the various dictionaries and resource persons, 7) the impacts of various irregularities to the TT reader are a) TT readers receive messages/information that are different from messages/information contained on the TS, b) TT readers get inaccurate information, c) the translation of the ST writer into Indonesian becomes pointless for the purpose of distributing Knowledge of discourse analysis is not fulfilled, this TT, does not meet the intended standard, d) the absence of intertextuality between the book of discourse analysis with other texts that examine or discuss various topics around the study of discourse.

Based on the research findings, the researcher put forward the following suggestions:

1. This research focuses only on textual equivalence on linguistic scientific texts, for which further research is needed, especially in relation to the study of textual equivalence in various translated texts, especially scientific texts in other fields of science.

2. In an interpreter teaching, this study can be recommended as one of the inputs (analysis and critique of translation), which can be used by teachers/lecturers in delivering material on translation studies, especially regarding the textual equivalence.

3. In the teaching and learning of foreign languages in the era multilingualism, multiculturalism driven by worldwide migration flows, the process of internationalization and technological development, translation is a form of exercise that is appropriate for the learners to learn the language in the context of la parole da $n$ la langue.

4. In the teaching and learning of languages, translation activity that involves translating various types of texts, will help learners to see the 'real world' that communicates a culture that underlies 
a foreign language. Therefore, through translation activities, learners can improve their crosscultural understanding.

5. Translation is a process that produces a product. As a process, the translation must be understood as an activity carried out by the internal knowledge perception (angle of view of the translator). From this point of view, the translator as the actor must know how the translation should be done.

6. Irregularities, and the impact of deviations on translated work, especially scientific texts, are essential to be input to all parties involved in translation efforts in Indonesia, which are lecturers, students, and publishers.

\section{REFERENCES}

Baker, Mona. In Other Words A Course Book of Translation. London dan New York: Routledge, 2011.

Emzir. MetodePenelitianKualitatif : Analisis Data. Jakarta: Rajawali Press, 2010.

Halliday, M.A.K, and C. Matthiesen An Introduction to Functional Grammar.London: Edward Arnold, 2004.

Hoed, Benny.H. PenerjemahandanKebudayaan. Jakarta: Pustaka Jaya, 2006.

House, Juliane. Translation. Oxford: Oxford University Press, 2009.

Munday, Jeremy. Introducing Translation Studies Theories and Applications. London danNew York: Routledge, 2008.

Newmark, Peter. Approaches to Translation. Oxford: Pergamon Press, 1981.

Nida, Eugene A. Context in Translating. Amsterdam/Philadelphia: John Benjamins B. V., 2001.

Panou, Despiona. Equivalence in Translation Theories: A CriticalEvaluation (Theory and Practice in Language Studies, January 2013 ISSN: 1799-2591 volume 3, No 1, pp 1-6)

William, Jenny and Andrew Chesterman. The Map A Beginner's to Doing Research in Translation Studies. Manchester: St Jerome Publishing, 2002. 